\title{
Development of Predictive Techniques for Estimating Liquid Water-Hydrate Equilibrium of Water-Hydrocarbon System
}

\author{
Amir H. Mohammadi and Dominique Richon \\ Laboratoire de Thermodynamique et des Équilibres entre Phases (TEP), Centre Énergétique et Procédés (CEP), \\ École Nationale Supérieure des Mines de Paris, 35 rue Saint-Honoré, 77305 Fontainebleau Cedex, France \\ Correspondence should be addressed to Dominique Richon, dominique.richon@ensmp.fr
}

Received 16 July 2008; Accepted 11 November 2008

Recommended by William Acree

In this communication, we review recent studies by these authors for modeling the $L_{W}-H$ equilibrium. With the aim of estimating the solubility of pure hydrocarbon hydrate former in pure water in equilibrium with gas hydrates, a thermodynamic model is introduced based on equality of water fugacity in the liquid water and hydrate phases. The solid solution theory of Van der Waals-Platteeuw is employed for calculating the fugacity of water in the hydrate phase. The Henry's law approach and the activity coefficient method are used to calculate the fugacities of the hydrocarbon hydrate former and water in the liquid water phase, respectively. The results of this model are successfully compared with some selected experimental data from the literature. A mathematical model based on feed-forward artificial neural network algorithm is then introduced to estimate the solubility of pure hydrocarbon hydrate former in pure water being in equilibrium with gas hydrates. Independent experimental data (not employed in training and testing steps) are used to examine the reliability of this algorithm successfully.

Copyright (C) 2009 A. H. Mohammadi and D. Richon. This is an open access article distributed under the Creative Commons Attribution License, which permits unrestricted use, distribution, and reproduction in any medium, provided the original work is properly cited.

\section{Introduction}

Gas hydrates are ice-like structures in which water molecules, under pressure, form structures composed of polyhedral cages surrounding gas molecule "guests" such as methane and ethane [1-4]. The most common gas hydrate structures are those of structure I $(s I)$ and structure II $(s I I)$, where each structure is composed of a certain number of large and small cavities formed by water molecules $[1,2]$. For a molecule to enter a cavity, its size should be smaller than a certain value. Large molecule guests which can enter only a limited number of large cavities require smaller "help gas" molecules to mainly fill some smaller cavities sufficiently to stabilize hydrate crystals $[1,2]$. It has been proved that gas hydrates occur in staggering abundance in cold subsea, sea floor, and permafrost environments where temperature and pressure conditions ensure their stability [1-5]. It is believed the amount of natural gas trapped in these deposits is much higher than the amount of natural gas existing in classical reserves $[1,2,5]$. Hydrate technology has also been proposed as a means for $\mathrm{CO}_{2}$ separation from industrial flue gases and sequestration in the deep ocean for reducing the emission of greenhouse gases [1-5]. Gas hydrates can form as well in undersea piping and above-ground pipelines, where they pose a major and expensive problem for the petroleum industry $[1,2]$. Hydrates are also being regarded as an alternate means of gas transportation and storage $[1,2,4]$. It is believed that the potential storage of gas in hydrate is comparable to gas storage in the form of liquefied natural gas $(L N G)$ and compressed natural gas $(C N G)[2,6]$.

The liquid water-hydrate $\left(L_{W}-H\right)$ equilibrium knowledge is necessary in the design of gas transportation and storage process and should be destined for proposed $\mathrm{CO}_{2}$ sequestration schemes $[1-4,6]$. These factors, and the potential widespread abundance of gas hydrates in the cold subsea, sea floor, and permafrost environments $[1-4,6]$, warrant an understanding of $L_{W}-H$ equilibrium.

Figure 1 shows typical solubility-temperature diagram for water-pure hydrate former (limiting reactant) system [2]. As can be seen, the temperature and pressure dependencies of the pure hydrate former solubility in pure water being in the liquid water-vapor $\left(L_{W}-V\right)$ equilibrium region are 


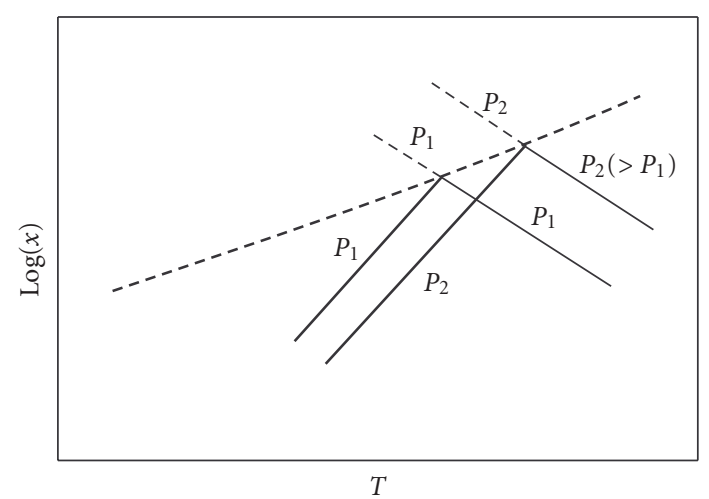

$$
\begin{array}{ll}
- & L_{W}-H \text { equilibrium } \\
- & L_{W}-V \text { equilibrium } \\
--- & L_{W}-V-H \text { equilibrium } \\
--- & \text { Metastable } L_{W}-V \text { equilibrium }
\end{array}
$$

Figure 1: Typical solubility $(x)$-temperature $(T)$ diagram for water-single (pure) hydrate former (limiting reactant) system. $L_{W}$ : liquid water; $H$ : hydrate; $V$ : vapor; $P$ : pressure [2]. Bold solid lines: $L_{W}-H$ equilibrium; solid lines: $L_{W}-V$ equilibrium; dashed lines: metastable $L_{W}-V$ equilibrium; bold dashed line: $L_{W}-V-H$ equilibrium.

different from the corresponding dependency in the $L_{W}-H$ equilibrium region $[1-4,6-19]$. The $L_{W}-V$ equilibrium is strong function of temperature and pressure while the $L_{W^{-}}$$H$ equilibrium is strong function of temperature but very weak function of pressure [1-4, 6-19]. On the other hand, the pure hydrate former solubility in pure water being in the $L_{W}-V$ equilibrium region increases with decreasing the temperature at a given pressure, while, the corresponding solubility in pure water being in the $L_{W}-H$ equilibrium region decreases with decreasing the temperature at the same pressure [1-4, 6-19]. Furthermore, the metastable liquid water-vapor $\left(L_{W}-V\right)$ equilibrium may extend well into the gas hydrate formation zone [1, 2, 6-19].

The experimental works done to describe the $L_{W}-H$ equilibrium are limited mainly due to two factors: the possible extension of the metastable $L_{W}-V$ equilibrium into the gas hydrate region and the experimental restraint that the existing analysis methods require modifications [1, 2, 6-19]. Literature survey reveals the availability of only few sets of experimental data for the $L_{W}-H$ equilibrium $[1,2,7,11,16-$ 19]. Consequently, few reliable models are available in the literature for calculating the $L_{W}-H$ equilibrium $[1-4,6-$ $8,11,14-16]$.

The objective of this work is to review recent studies by these authors for modeling the $L_{W}-H$ equilibrium [2-4]. A thermodynamic model based on equality of water fugacity in the liquid water and hydrate phases for determining solubility of pure hydrocarbon hydrate former in pure water being in equilibrium with gas hydrates is first introduced [2]. The fugacity of water in the hydrate phase is calculated using the solid solution theory of van der Waals-Platteeuw [20]. The hydrocarbon hydrate former fugacity and water fugacity in the liquid water phase are calculated using Henry's law approach and the activity coefficient method, respectively. The capability of this model is investigated by comparing its predictions with some selected experimental data from the literature. It is demonstrated that the results are in acceptable agreement demonstrating the capability of the thermodynamic model developed in this work for estimating the solubility of pure hydrocarbon hydrate former in pure water being in equilibrium with gas hydrates. It is also shown that by assuming an average value equal to 1.2 for the water activity coefficient, acceptable results can be obtained for estimating the solubility of carbon dioxide in water at equilibrium with its gas hydrate [3]. Finally, the capability of artificial neural network ( $A N N$ ) algorithm, as an alternative tool, for modeling the $L_{W}-H$ equilibrium is successfully demonstrated [4].

\section{Liquid Water-Hydrate Equilibrium}

The liquid water-hydrate equilibrium of a system is calculated, by equating the fugacities of water in the liquid water phase, $f_{w}^{L}$, and in the hydrate phase, $f_{w}^{H}$, as follows [1-3]:

$$
f_{w}^{L}=f_{w}^{H} .
$$

The fugacity of water in the hydrate phase, $f_{w}^{H}$, is related to the chemical potential difference of water in the filled and empty hydrate cages by the following expression $[1,2]$ :

$$
f_{w}^{H}=f_{w}^{M T} \exp \frac{\mu_{w}^{H}-\mu_{w}^{M T}}{R T},
$$

where $f_{w}^{M T}$ is the fugacity of water in the hypothetical empty hydrate phase and $\mu_{w}^{H}-\mu_{w}^{M T}$ represents the chemical potential difference of water in the filled $\left(\mu_{w}^{H}\right)$ and empty $\left(\mu_{w}^{M T}\right)$ hydrates. $R$ and $T$ stand for universal gas constant and temperature, respectively.

The solid solution theory of van der Waals-Platteeuw [20] can be employed for calculating $\left(\mu_{w}^{H}-\mu_{w}^{M T}\right) / R T$ as follows $[1,2]$ :

$$
\begin{aligned}
\frac{\mu_{w}^{H}-\mu_{w}^{M T}}{R T} & =-\sum_{i} v_{i}^{\prime} \ln \left(1+\sum_{j} C_{i j} f_{j}\right) \\
& =\sum_{i} \ln \left(1+\sum_{j} C_{i j} f_{j}\right)^{-v_{i}^{\prime}},
\end{aligned}
$$

where $v_{i}^{\prime}$ is the number of cavities of type $i$ per water molecule in a unit hydrate cell $[1,2], C_{i j}$ stands for the Langmuir constant for hydrocarbon hydrate former's interaction with each type cavity, and $f_{j}$ is the fugacity of hydrate former [2].

The fugacity of water in the empty lattice can be expressed as follows $[1,2]$ :

$$
f_{w}^{M T}=P_{w}^{M T} \varphi_{w}^{M T} \exp \int_{P_{w}^{M T}}^{P} \frac{v_{w}^{M T} d P}{R T},
$$

where $P_{w}^{M T}, \varphi_{w}^{M T}, v_{w}^{M T}$, and $P$ are the vapor pressure of the empty hydrate lattice, the correction for the deviation of the saturated vapor of the pure (hypothetical) lattice from ideal 
behavior, the partial molar volume of water in the empty hydrate $[1,2,21]$, and pressure, respectively. The exponential term is a Poynting type correction.

Equation (4) may be simplified by two assumptions: (1) that the hydrate partial molar volume equals to the molar volume and is independent of pressure and (2) that $P_{w}^{M T}$ is relatively small (on the order of $10^{-3} \mathrm{MPa}$ ), so that $\varphi_{w}^{M T}=1$ $[1,2]$. Therefore $[1,2]$,

$$
f_{w}^{M T}=P_{w}^{M T} \times \exp \frac{v_{w}^{M T}\left(P-P_{w}^{M T}\right)}{R T} .
$$

Using the previous expressions, the following equation is obtained for the fugacity of water in the hydrate phase [2]:

$$
\begin{aligned}
f_{w}^{H}= & P_{w}^{M T} \times \exp \left[\frac{v_{w}^{M T}\left(P-P_{w}^{M T}\right)}{R T}\right] \\
& \times\left[\left(1+C_{\text {small }} f_{H C}^{L}\right)^{-v_{\text {small }}^{\prime}} \times\left(1+C_{\text {large }} f_{H C}^{L}\right)^{-v_{\text {large }}^{\prime}}\right],
\end{aligned}
$$

where $f_{H C}^{L}$ is the fugacity of hydrocarbon hydrate former in the liquid water phase.

The Poynting correction term can be ignored up to intermediate pressures and therefore, the following equation can be obtained for calculating fugacity of water in hydrate phase $[2,3]$ :

$$
f_{w}^{H}=P_{w}^{M T} \times\left[\left(1+C_{\text {small }} f_{H C}^{L}\right)^{-v_{\text {small }}^{\prime}} \times\left(1+C_{\text {large }} f_{H C}^{L}\right)^{-v_{\text {large }}^{\prime}}\right] .
$$

The fugacity of water in the liquid water phase can be expressed by $[2,3,22]$ :

$$
f_{w}^{L}=x_{w}^{L} \gamma_{w}^{L} P_{w}^{\text {sat }},
$$

where $x_{w}^{L}$ and $\gamma_{w}^{L}$ are, respectively, the water mole fraction and the activity coefficient of water in liquid water phase being in equilibrium with gas hydrates. In the intermediate pressure range, the liquid water is an incompressible fluid, hydrocarbon hydrate former solubility is very small comparing to unity, and activity coefficient of water can be approximated to unity [22] (however it is necessary to be careful, as it is not the case at high pressures [22] where the nonideality of the liquid water phase and solubility become important). Therefore, (8) can be satisfactorily written as follows [2]:

$$
f_{w}^{L} \cong P_{w}^{\text {sat }} .
$$

Using (7) and (9), the following expression is obtained [2]:

$$
P_{w}^{s a t}=P_{w}^{M T} \times\left[\left(1+C_{\text {small }} f_{H C}^{L}\right)^{-v_{\text {small }}^{\prime}} \times\left(1+C_{\text {large }} f_{H C}^{L}\right)^{-v_{\text {large }}^{\prime}}\right]
$$

or

$$
\begin{aligned}
1-\left(\frac{P_{w}^{M T}}{P_{w}^{\text {sat }}}\right) \times[ & \left(1+C_{\text {small }} f_{H C}^{L}\right)^{-v_{\text {small }}^{\prime}} \\
& \left.\times\left(1+C_{\text {large }} f_{H C}^{L}\right)^{-v_{\text {large }}^{\prime}}\right]=0,
\end{aligned}
$$

where the fugacity of hydrocarbon hydrate former in the liquid water phase up to intermediate pressures can be calculated using the following equation $[2,22]$ :

$$
f_{H C}^{L}=x_{H C}^{L} \bar{H}_{H C-w},
$$

where $\bar{H}_{H C-w}$ represents Henry's constant for hydrocarbon hydrate former-water system. Therefore, the following final expression is obtained for estimating the solubility of pure hydrocarbon hydrate former in liquid water phase being in equilibrium with gas hydrates [2]:

$$
\begin{aligned}
1-\left(\frac{P_{w}^{M T}}{P_{w}^{\text {sat }}}\right) \times[ & \left(1+C_{\text {small }} x_{H C}^{L} \bar{H}_{H C-w}\right)^{-v_{\text {small }}^{\prime}} \\
& \left.\times\left(1+C_{\text {large }} x_{H C}^{L} \bar{H}_{H C-w}\right)^{-v_{\text {large }}^{\prime}}\right]=0 .
\end{aligned}
$$

Equation (13a) allows easy calculation of the solubility of pure hydrocarbon hydrate former in the liquid water being in equilibrium with gas hydrates. Its main advantages are the availability of necessary input data and the simplicity of the calculations, as the calculations can be done in Excel spread sheets [2]. Furthermore, as can be seen in (13a), almost all terms are temperature dependent while not pressure dependent, indicating the solubility of pure hydrocarbon hydrate former in liquid water phase being in equilibrium with gas hydrates is strong function of temperature and only very weak function of pressure. For the $\mathrm{CO}_{2}$ (and other highly soluble gases like $\mathrm{H}_{2} \mathrm{~S}$ )-water system, the solubility of $\mathrm{CO}_{2}$ in the water phase cannot be ignored and consequently, the water activity cannot be set to unity. Taking into account the $\mathrm{CO}_{2}$ solubility in the water phase and also the water activity, the following equation can be derived [3]:

$$
\begin{aligned}
& 1-\left[\frac{P_{w}^{M T}}{\left(1-x_{\mathrm{CO}_{2}}^{L}\right) \gamma_{w}^{L} P_{w}^{\text {sat }}}\right] \\
& \quad \times\left[\left(1+C_{\mathrm{small}} x_{\mathrm{CO}_{2}}^{L} \bar{H}_{\mathrm{CO}_{2-w}}\right)^{-v_{\text {small }}^{\prime}}\right. \\
& \left.\quad \times\left(1+C_{\text {large }} x_{\mathrm{CO}_{2}}^{L} \bar{H}_{\mathrm{CO}_{2-w}}\right)^{-v_{\text {large }}^{\prime}}\right]=0 .
\end{aligned}
$$

2.1. Model Parameters. In (13a) and (13b), the following values of $v_{i}^{\prime}$ for structure-I hydrates can be used $[1,2]$ :

$$
\begin{aligned}
& v_{\text {small }}^{\prime}=\frac{1}{23}, \\
& v_{\text {large }}^{\prime}=\frac{3}{23},
\end{aligned}
$$

and for structure II:

$$
\begin{aligned}
& v_{\text {small }}^{\prime}=\frac{2}{17}, \\
& v_{\text {large }}^{\prime}=\frac{1}{17} .
\end{aligned}
$$

The Langmuir constants (they are generally functions of temperature, pressure, composition and hydrate structure, while the effect of pressure is normally ignored [23]) accounting for the interaction between the hydrate former and water molecules in the cavities were reported by Parrish 
TABLE 1: Constants $a-d$ in (15) and (16) [24].

\begin{tabular}{lcccc}
\hline $\begin{array}{l}\text { Hydrate } \\
\text { former }\end{array}$ & $a /\left(\mathrm{K}_{\mathrm{MPa}} \mathrm{MP}^{-1}\right)$ & $b /\left(\mathrm{K} \cdot \mathrm{MPa}^{-1}\right)$ & $c /\left(\mathrm{K} \cdot \mathrm{MPa}^{-1}\right)$ & $d /\left(\mathrm{K} \cdot \mathrm{MPa}^{-1}\right)$ \\
\hline Methane & 0.0037237 & 2708.8 & 0.018373 & 2737.9 \\
Ethane & 0 & 0 & 0.006906 & 3631.6 \\
Propane & 0 & 0 & 0.012353 & 4406.1 \\
$\mathrm{CO}_{2}$ & 0.0011978 & 2860.5 & 0.008507 & 3277.9
\end{tabular}

and Prausnitz [24] for a range of temperatures and hydrate formers [2]. However, the integration procedure was already followed in obtaining the Langmuir constants for wider temperatures using the Kihara [25] potential function with a spherical core according to the study by McKoy and Sinanoğlu [26]. In this work, the Langmuir constants for hydrate former's interaction with each type cavity have been determined using the equations of Parrish and Prausnitz [24]:

For pentagonal dodecahedra (small cavity):

$$
C_{\text {small }}=\frac{a}{T} \times \exp \left(\frac{b}{T}\right),
$$

for tetrakaidecahedra (large cavity):

$$
C_{\text {large }}=\frac{c}{T} \times \exp \left(\frac{d}{T}\right),
$$

where $T$ is in $\mathrm{K}$ and $C$ has units of reciprocal MPa. Constants $a-d$ are reported in Table 1 .

The concept in (4) of universal empty hydrate vapor pressure for each structure prompted Dharmawardhana et al. [27] to calculate the $P_{w}^{M T}$ from a number of simple hydrate three-phase ice-vapor-hydrate equilibrium. By equating the fugacity of water in the hydrate phase to that of pure ice at the three-phase line, Dharmawardhana et al. [27] obtained the following equation for the vapor pressure of the empty hydrate structure I $[1,2]$ :

$$
P_{w}^{M T}=0.1 \times \exp \left(17.440-\frac{6003.9}{T}\right)
$$

and for structure II:

$$
P_{w}^{M T}=0.1 \times \exp \left(17.332-\frac{6017.6}{T}\right),
$$

where $P_{w}^{M T}$ is in MPa and $T$ is in $\mathrm{K}$. It should be mentioned that the nonideality of water vapor pressure of the empty hydrate at saturation seems to be negligible due to the small quantity (typically, $10^{-3}$ to $10^{-5} \mathrm{MPa}$ ).

The following values for Henry's constant of hydrocarbon hydrate former-water can be used $[2,28]$ :

$$
\bar{H}_{g, w}(T)=\left(10^{A+B / T+\bar{C} \times \log (T)+D \times T}\right) \times 0.1,
$$

where $T$ and $\bar{H}_{g, w}(T)$ are in $\mathrm{K}$ and $\mathrm{MPa}$, respectively. Constants $A, B, \bar{C}$, and $D$ are given in Table 2 .
Table 2: Constants $A-D$ in (18) [28].

\begin{tabular}{lcccccc}
\hline $\begin{array}{l}\text { Hydrate } \\
\text { former }\end{array}$ & $A$ & $B / \mathrm{K}$ & $\overline{\mathrm{C}} / \mathrm{K}^{-1}$ & $D / \mathrm{K}^{-1}$ & $T_{\min }$ & $T_{\max }$ \\
\hline Methane & 147.788 & -5768.3 & -52.2952 & 0.018616 & 273.15 & 373.15 \\
Ethane & 146.901 & -5768.3 & -51.8593 & 0.017410 & 273.15 & 343.15 \\
$\mathrm{CO}_{2}$ & 21.6215 & -1499.8 & -5.64947 & 0.0002062 & 273.15 & 373.15 \\
\hline
\end{tabular}

For the propane-water system the following equation was used: $\bar{H}_{\text {propane }, w}(T)=10^{-3} \times \exp \{552.648+0.078453 \times T-(21334.4 / T)-$ $85.89736 \times \ln (T)\}$.

The water vapor pressure can be obtained using the following expression [29]:

$$
\begin{gathered}
P_{w}^{\text {sat }}=10^{-6} \exp \left(73.649-\frac{7258.2}{T}-7.3037 \ln (T)\right. \\
\left.+4.1653 \times 10^{-6} T^{2}\right)
\end{gathered}
$$

where, $T$ and $P_{w}^{\text {sat }}$ are, respectively, in $\mathrm{K}$ and $\mathrm{MPa}$.

\section{Artificial Neural Network Algorithm}

Artificial neural networks have large numbers of computational units called neurons connected in a massively parallel structure and do not need an explicit formulation of the mathematical or physical relationships of the handled problem [4, 30-37]. The most commonly used ANNs are the feed-forward neural networks (FNN) $[4,36,37]$, which are designed with one input layer, one output layer and hidden layers $[4,33-35,37]$. The number of neurons in the input and output layers equals to the number of inputs and outputs physical quantities, respectively $[4,37]$. The disadvantage of FNNs is the determination of the ideal number of neurons in the hidden layer(s); few neurons produce a network with low precision and a higher number leads to overfitting and bad quality of interpolation and extrapolation $[4,37]$. The use of techniques such as Bayesian regularization, along with a Levenberg-Marquardt algorithm [4, 38, 39], can help overcome this problem $[4,31,32,37]$.

In the FNN method, the input layer of the network receives all the input data and introduces scaled data to the network $[4,37]$. The data from the input neurons are propagated through the network via weighted interconnections [4, 37]. Every $i$ neuron in a $k$ layer is connected to every neuron in adjacent layers $[4,37]$. The $i$ neuron within the hidden $k$ layer performs the following tasks: summation of the arriving weighted inputs (input vector $I_{i}=\left[I_{i, 1}, \ldots, I_{i, N k-1}\right]$ ) and propagations of the resulting summation through an activation function, $\bar{f}$, to the adjacent neurons of the next hidden layer or to the output neuron(s). Three types of transfer functions are normally used: the exponential sigmoid, tangent sigmoid and linear functions $[4,37]$. In this work, the activation function is a linear function [4]:

$$
\bar{f}(\bar{x})=\bar{x},
$$

where $\bar{x}$ stands for parameter of linear activation function. A bias term, $\bar{b}$, is associated with each interconnection in 
order to introduce a supplementary degree of freedom. The expression of the weighted sum, $S$, to the $i$ th neuron in the $k$ th layer $(k \geq 2)$ is $[4,37]$ :

$$
S_{k, i}=\sum_{j=1}^{N_{k-1}}\left[\left(w_{k-1, j, i} I_{k-1, j}\right)+\bar{b}_{k, i}\right],
$$

where $w$ is the weight parameter between each neuronneuron interconnection. Using this feed-forward network with linear activation function, the output, $O$, of the $i$ neuron within the hidden $k$ layer is [4]:

$$
O_{k, i}=S_{k, i}
$$

To achieve a better stability, the following scaling rule is applied to solubility of pure hydrocarbon hydrate former being in equilibrium with gas hydrates $(x)$ before normalization [4]:

$$
x_{\text {Network }}=\log \left(x_{\exp }\right),
$$

where subscript exp represents experimental data.

To develop the ANN, the datasets are subdivided into 3 classes: training, testing and validation [4, 37]. After partitioning the datasets, the training set is used to adjust the parameters. All synaptic weights and biases are first initialized randomly. The network is then trained; its synaptic weights are adjusted by optimization algorithm, until it correctly emulates the input/output mapping, by minimizing the average root-mean-square error $[4,37]$. The optimization method chosen in this work was the LevenbergMarquardt algorithm [38, 39], as mentioned earlier. The testing set is used during the adjustment of the network's synaptic weights to evaluate the algorithms performance on the data not used for adjustment and stop the adjusting if the error on the testing set increases. Finally, the validation set measures the generalization ability of the model after the fitting process $[4,37]$.

\section{Results and Discussion}

4.1. Thermodynamic Model. Among the $L_{W}-H$ equilibrium data reported in the literature for the solubility of methane in pure water being in equilibrium with gas hydrates, those reported by Yang [16], Servio and Englezos [10] and Kim et al. [11] seem to be the most reliable. These data are reported in Tables 3, 4, and 5, respectively. As can be seen, the temperature range is from 274.15 to $281.7 \mathrm{~K}$, and the pressures are up to $143.62 \mathrm{MPa}$. Other experimental data reported in the literature for methane solubility in pure water being in equilibrium with gas hydrates have not been considered in this work, as they are not consistent with other literature data. Tables 3-5 also show the predictions of the models developed in this work and the absolute deviations $(A D s)$. As can be seen, (13a) with no adjustable parameter shows encouraging results. The predictions of this thermodynamic model for the solubility of methane in pure water being in equilibrium with gas hydrates show less than $18 \%$ absolute deviation and the average absolute deviation
$(A A D)$ among all the experimental and predicted data is $7.3 \%[4]$.

Limited information is available for the $L_{W}-H$ equilibrium of ethane + water system. Yang [16] and Kim et al. [11] measured ethane solubility in pure water being in equilibrium with gas hydrates. These experimental data along with the predictions of (13a) and $A D s$ are shown in Tables 6 and 7. As can be observed, the temperature range is from 277.3 to $278.5 \mathrm{~K}$, and the pressures are up to $151 \mathrm{MPa}$. This table also shows that the temperature change has no effect on experimental gas solubility data $[11,16]$ indicating the experimental data reported by Yang [16] and Kim et al. [11] for ethane solubility in pure water being in equilibrium with gas hydrates are not reliable. The maximum $A D$ between the experimental and predicted data for the ethane + water system is less than $32 \%$ and the $A A D$ is less than $22 \%[4]$.

Limited information is also available for the propane solubility in pure water being in equilibrium with gas hydrates. Gaudette and Servio [19] measured these data, which are reported in Table 8 . As can be seen, the temperature range is from 274.16 to $276.16 \mathrm{~K}$, and the pressures are up to $0.358 \mathrm{MPa}$. The $A A D$ is equal to $8 \%$ and the maximum $A D$ between the experimental and predicted data is less than $17 \%$. For this system, the vapor pressure of the empty hydrate lattice in the thermodynamic model was slightly tuned, because it can be regarded as one of the deviations sources in the thermodynamic model $[1,4]$.

Among the $L_{W}-H$ equilibrium data reported in the literature for the $\mathrm{CO}_{2}$ solubility in pure water at equilibrium with its gas hydrate, those reported by Servio and Englezos [9] and Yang et al. [7] seem to be the most reliable. These data are reported in Tables 9 and 10, respectively. As can be seen, the temperature range is from 273.95 to $282.95 \mathrm{~K}$, and the pressures are up to $14.2 \mathrm{MPa}$. Tables 9 and 10 also show the predictions of the thermodynamic model used in this work and the absolute deviations. In this table, the experimental data reported at $275.95 \mathrm{~K}$ and $2 \mathrm{MPa}$ was used to adjust the activity coefficient of water in (13b). An average value equal to 1.2 yielded very good results $(A D=0 \%)$. Using this value for the activity coefficient of water, (13b) was applied to predict the $\mathrm{CO}_{2}$ solubility in pure water at equilibrium with its gas hydrate. As demonstrated in Tables 9 and 10, (13b) shows encouraging results. The predictions show less than $14 \%$ absolute deviation and the average absolute deviation among all the experimental and predicted data is less than $7 \%$. The average value equal to 1.2 eliminates any need to use a model for the activity coefficient of water reconfirming the simplicity of the model for predicting solubility of carbon dioxide in pure water at equilibrium with its gas hydrate [3].

In addition to the quality of the experimental data reported in the literature, the deviations may be attributed to other factors, as well: the Langmuir constants and the vapor pressures of the empty hydrate lattice are consistent with initial data on the liquid water/ice-vapor-hydrate equilibrium. Since the experimental conditions go far below the initial hydrate formation conditions, the assumptions that are evidently valid at the initial hydrate formation conditions 
TABLE 3: Experimental [16] and predicted/calculated solubility of methane in pure water being in equilibrium with gas hydrates (liquid water-hydrate equilibrium) [4].

\begin{tabular}{|c|c|c|c|c|c|c|}
\hline$T / \mathrm{K}$ & $P / \mathrm{MPa}$ & $\begin{array}{c}\text { Experimental }[16] \\
\text { methane solubility/mole } \\
\text { fraction }\left(\times 10^{3}\right)\end{array}$ & $\begin{array}{l}\text { Predicted/calculated } \\
\text { methane solubility using } \\
\text { ANN algorithm/mole } \\
\text { fraction }\left(\times 10^{3}\right)\end{array}$ & $A D \%$ & $\begin{array}{l}\text { Predicted methane } \\
\text { solubility using } \\
\text { thermodynamic } \\
\text { model/mole fraction } \\
\qquad\left(\times 10^{3}\right)\end{array}$ & $A D \%^{\dagger}$ \\
\hline 276.19 & 50.00 & $1.25^{* *}$ & 1.29 & 3.2 & 1.40 & 12.0 \\
\hline 277.85 & 50.81 & 1.50 & 1.44 & 4.0 & 1.55 & 3.3 \\
\hline 279.85 & 50.98 & $1.65^{*}$ & 1.65 & 0.0 & 1.74 & 5.5 \\
\hline 280.47 & 51.26 & 1.75 & 1.72 & 1.7 & 1.81 & 3.4 \\
\hline 276.36 & 101.00 & 1.25 & 1.30 & 4.0 & 1.42 & 13.6 \\
\hline 278.71 & 101.73 & 1.50 & 1.53 & 2.0 & 1.63 & 8.7 \\
\hline 280.11 & 101.88 & 1.65 & 1.68 & 1.8 & 1.77 & 7.3 \\
\hline 280.65 & 102.43 & 1.75 & 1.74 & 0.6 & 1.83 & 4.6 \\
\hline 276.67 & 127.10 & 1.25 & 1.33 & 6.4 & 1.44 & 15.2 \\
\hline 278.90 & 127.22 & 1.50 & 1.55 & 3.3 & 1.65 & 10.0 \\
\hline 280.39 & 127.35 & 1.65 & 1.71 & 3.6 & 1.80 & 9.1 \\
\hline 281.08 & 127.45 & $1.75^{* *}$ & 1.79 & 2.3 & 1.87 & 6.9 \\
\hline 276.91 & 143.10 & 1.25 & 1.35 & 8.0 & 1.47 & 17.6 \\
\hline 279.20 & 143.62 & 1.50 & 1.58 & 5.3 & 1.68 & 12.0 \\
\hline 280.59 & 143.25 & 1.65 & 1.73 & 4.8 & 1.82 & 10.3 \\
\hline 281.65 & 143.24 & 1.75 & 1.86 & 6.3 & 1.94 & 10.9 \\
\hline
\end{tabular}

* Data used for testing.

** Data used for validation (the remaining data were used for training).

${ }^{\dagger} A D=\mid($ experimental value - predicted/calculated value $) /$ experimental value $\mid$.

TABLE 4: Experimental [10] and predicted/calculated solubility of methane in pure water being in equilibrium with gas hydrates (liquid water-hydrate equilibrium) [4].

\begin{tabular}{|c|c|c|c|c|c|c|}
\hline$T / \mathrm{K}$ & $P / \mathrm{MPa}$ & $\begin{array}{c}\text { Experimental }[10] \\
\text { methane solubility/mole } \\
\text { fraction }\left(\times 10^{3}\right)\end{array}$ & $\begin{array}{l}\text { Predicted/calculated } \\
\text { methane solubility using } \\
\text { ANN algorithm/mole } \\
\text { fraction }\left(\times 10^{3}\right)\end{array}$ & $A D \%$ & $\begin{array}{l}\text { Predicted methane } \\
\text { solubility using } \\
\text { thermodynamic } \\
\text { model/mole fraction } \\
\quad\left(\times 10^{3}\right)\end{array}$ & $A D \%$ \\
\hline 274.35 & 3.5 & 1.170 & 1.14 & 2.6 & 1.26 & 7.7 \\
\hline 275.45 & 3.5 & $1.203^{*}$ & 1.23 & 2.2 & 1.34 & 11.4 \\
\hline 274.15 & 5.0 & 1.190 & 1.12 & 5.9 & 1.25 & 5.0 \\
\hline 277.35 & 5.0 & 1.360 & 1.39 & 2.2 & 1.50 & 10.3 \\
\hline 275.25 & 6.5 & 1.201 & 1.21 & 0.7 & 1.33 & 10.7 \\
\hline 280.15 & 6.5 & $1.567^{* *}$ & 1.68 & 7.2 & 1.77 & 13.0 \\
\hline
\end{tabular}

* Data used for testing.

** Data used for validation (the remaining data were used for training).

may be invalid elsewhere [1]. Accurate determination of fugacities has also important effect on the predictions. Henry's law approach for calculating fugacities of pure and heavy hydrocarbon hydrate formers may not be very accurate, as Henry's constants are normally developed based on experimental data and measuring these data for heavy hydrocarbon hydrate formers may not be easy [2-4].

4.2. Artificial Neural Network Algorithm. The ANN algorithm detailed in Table 11 with one hidden layer was used to calculate/predict the logarithm of solubility of pure hydrocarbon hydrate former in pure water being in equilibrium with gas hydrates as a function of temperature and carbon number of hydrocarbon hydrate former (which represents the type of hydrocarbon), because the logarithm of solubility is approximately linear function of temperature for a given pure hydrocarbon hydrate former. It should be mentioned that plenty of data should generally be used for developing $A A N$ algorithms, especially for highly nonlinear systems. In our case, where the logarithm of solubility of pure hydrocarbon hydrate former in pure water being in equilibrium with gas hydrates is approximately linear function of temperature, few sets of data for training (data reported in Tables 3-8) can be used to develop the ANN 
TABLE 5: Experimental [11] and predicted/calculated solubility of methane in pure water being in equilibrium with gas hydrates (liquid water-hydrate equilibrium) [4].

\begin{tabular}{|c|c|c|c|c|c|c|}
\hline$T / \mathrm{K}$ & $P / \mathrm{MPa}$ & $\begin{array}{c}\text { Experimental }[11] \\
\text { methane solubility/mole } \\
\text { fraction }\left(\times 10^{3}\right)\end{array}$ & $\begin{array}{l}\text { Predicted/calculated } \\
\text { methane solubility using } \\
\text { ANN algorithm/mole } \\
\text { fraction }\left(\times 10^{3}\right)\end{array}$ & $A D \%$ & $\begin{array}{l}\text { Predicted methane } \\
\text { solubility using } \\
\text { thermodynamic } \\
\text { model/mole fraction } \\
\qquad\left(\times 10^{3}\right)\end{array}$ & $A D \%$ \\
\hline 276.2 & 5.0 & 1.33 & 1.29 & 3.0 & 1.40 & 5.3 \\
\hline 277.9 & 5.1 & 1.59 & 1.45 & 8.8 & 1.55 & 2.5 \\
\hline 279.9 & 5.1 & 1.75 & 1.66 & 5.1 & 1.75 & 0.0 \\
\hline 280.5 & 5.1 & 1.86 & 1.72 & 7.5 & 1.81 & 2.7 \\
\hline 276.4 & 10.1 & $1.33^{*}$ & 1.31 & 1.5 & 1.41 & 6.0 \\
\hline 278.7 & 10.2 & 1.59 & 1.53 & 3.8 & 1.42 & 10.7 \\
\hline 280.1 & 10.2 & 1.75 & 1.68 & 4.0 & 1.77 & 1.1 \\
\hline 280.7 & 10.2 & 1.86 & 1.75 & 5.9 & 1.84 & 1.1 \\
\hline 276.7 & 12.7 & 1.33 & 1.33 & 0.0 & 1.45 & 9.0 \\
\hline 278.9 & 12.7 & $1.59^{* *}$ & 1.55 & 2.5 & 1.65 & 3.8 \\
\hline 280.4 & 12.7 & 1.75 & 1.71 & 2.3 & 1.80 & 2.9 \\
\hline 281.1 & 12.7 & 1.86 & 1.79 & 3.8 & 1.88 & 1.1 \\
\hline 276.9 & 14.3 & 1.33 & 1.35 & 1.5 & 1.46 & 9.8 \\
\hline 279.2 & 14.4 & 1.59 & 1.58 & 0.6 & 1.68 & 5.7 \\
\hline 280.6 & 14.3 & 1.75 & 1.73 & 1.1 & 1.82 & 4.0 \\
\hline 281.7 & 14.3 & $1.88^{* *}$ & 1.87 & 0.5 & 1.94 & 3.2 \\
\hline
\end{tabular}

* Data used for testing.

** Data used for validation (the remaining data were used for training).

TABLE 6: Experimental [16] and predicted solubility of ethane in pure water being in equilibrium with gas hydrates (liquid water-hydrate equilibrium) [4].

\begin{tabular}{lccccc}
\hline T/K & P/MPa & $\begin{array}{c}\text { Experimental [16] } \\
\text { ethane solubility/mole } \\
\text { fraction }\left(\times 10^{4}\right)^{*}\end{array}$ & $\begin{array}{c}\text { Predicted ethane } \\
\text { solubility using } A N N \\
\text { algorithm/mole fraction } \\
\left(\times 10^{4}\right)\end{array}$ & $A D \%$ & $\begin{array}{c}\text { Predicted ethane } \\
\text { solubility using } \\
\text { thermodynamic } \\
\text { model/mole fraction } \\
\left(\times 10^{4}\right)\end{array}$ \\
\hline 277.31 & 51 & 4.12 & 5.00 & 21.4 & 4.91 \\
277.82 & 101 & 4.12 & 5.17 & 25.5 & 5.13 \\
278.46 & 151 & 4.12 & 5.40 & 31.1 & 5.42 \\
\hline
\end{tabular}

* Experimental solubility data are not temperature dependent and cannot be considered reliable. Therefore, the pseudo-experimental data generated from the thermodynamic model were used for training.

TABLE 7: Experimental [11] and predicted solubility of ethane in pure water being in equilibrium with gas hydrates (liquid water-hydrate equilibrium) [4].

\begin{tabular}{cccccc}
\hline T/K & P/MPa & $\begin{array}{c}\text { Experimental [1] } \\
\text { ethane solubility/mole } \\
\text { fraction }\left(\times 10^{4}\right)^{*}\end{array}$ & $\begin{array}{c}\text { Predicted ethane } \\
\text { solubility using } A N N \\
\text { algorithm/mole fraction } \\
\left(\times 10^{4}\right)\end{array}$ & $A D \%$ & $\begin{array}{c}\text { Predicted ethane } \\
\text { solubility using } \\
\text { thermodynamic } \\
\text { model/mole fraction } \\
\left(\times 10^{4}\right)\end{array}$ \\
\hline 277.3 & 10.1 & 4.37 & 5.00 & 14.4 & 4.90 \\
277.8 & 15.1 & 4.37 & 5.17 & 18.3 & 5.12 \\
278.5 & 20.1 & 4.37 & 5.42 & 24.0 & 5.43 \\
\hline
\end{tabular}

* Experimental solubility data are not temperature dependent and cannot be considered reliable. Therefore, the pseudo-experimental data generated from the thermodynamic model were used for training. 
TABLE 8: Experimental [19] and predicted/calculated solubility of propane in pure water being in equilibrium with gas hydrates (liquid water-hydrate equilibrium) [4].

\begin{tabular}{|c|c|c|c|c|c|c|}
\hline$T / \mathrm{K}$ & $P / \mathrm{MPa}$ & $\begin{array}{l}\text { Experimental [19] } \\
\text { propane solubility/mole } \\
\text { fraction }\left(\times 10^{4}\right)\end{array}$ & $\begin{array}{l}\text { Predicted/calculated } \\
\text { propane solubility using } \\
\text { ANN algorithm/mole } \\
\text { fraction }\left(\times 10^{4}\right)\end{array}$ & $A D \%$ & $\begin{array}{l}\text { Predicted propane } \\
\text { solubility using } \\
\text { thermodynamic } \\
\text { model/mole fraction } \\
\qquad\left(\times 10^{4}\right)^{\dagger}\end{array}$ & $A D \%$ \\
\hline 274.16 & 0.301 & $1.440^{*}$ & 1.45 & 0.7 & 1.34 & 6.9 \\
\hline 274.23 & 0.253 & 1.439 & 1.46 & 1.5 & 1.32 & 8.3 \\
\hline 274.33 & 0.358 & 1.546 & 1.47 & 4.9 & 1.54 & 0.4 \\
\hline 275.20 & 0.302 & 1.572 & 1.56 & 0.8 & 1.54 & 2.0 \\
\hline 275.20 & 0.352 & 1.572 & 1.56 & 0.8 & 1.79 & 13.9 \\
\hline 276.16 & 0.355 & $1.642^{* *}$ & 1.66 & 1.1 & 1.37 & 16.6 \\
\hline
\end{tabular}

* Data used for testing.

** Data used for validation (the remaining data were used for training).

tThe vapor pressure of the empty hydrate lattice in the thermodynamic model for propane hydrate was slightly tuned.

TABLE 9: Experimental [9] and predicted/calculated solubility of $\mathrm{CO}_{2}$ in water at equilibrium with gas hydrates (liquid water-hydrate equilibrium) [3].

\begin{tabular}{|c|c|c|c|c|}
\hline$T / K$ & $P / \mathrm{MPa}$ & $\begin{array}{c}\text { Experimental } \mathrm{CO}_{2} \\
\text { solubility }[9] / \mathrm{mole} \\
\text { fraction }\end{array}$ & $\begin{array}{l}\text { Predicted/calculated } \\
\mathrm{CO}_{2} \text { solubility using } \\
\text { thermodynamic } \\
\text { model/mole fraction }\end{array}$ & $A D \%$ \\
\hline 275.95 & 2.0 & $0.0173^{*}$ & 0.0173 & 0.0 \\
\hline 273.95 & 2.0 & 0.0164 & 0.0141 & 14.0 \\
\hline 277.05 & 3.7 & 0.0196 & 0.0183 & 6.6 \\
\hline 274.15 & 3.7 & 0.0158 & 0.0143 & 9.5 \\
\hline 278.15 & 4.2 & 0.0198 & 0.0200 & 1.0 \\
\hline 274.05 & 4.2 & 0.0156 & 0.0142 & 9.0 \\
\hline 274.05 & 5.0 & 0.0163 & 0.0142 & 12.9 \\
\hline 278.05 & 5.0 & 0.0198 & 0.0199 & 0.5 \\
\hline 282.85 & 5.0 & 0.0275 & 0.0305 & 10.9 \\
\hline 274.25 & 6.0 & 0.0163 & 0.0155 & 4.9 \\
\hline 276.45 & 6.0 & 0.0192 & 0.0187 & 2.6 \\
\hline 282.95 & 6.0 & 0.0281 & 0.0308 & 9.6 \\
\hline
\end{tabular}

*This experimental data was used to adjust the activity coefficient of water.

algorithm. However, the more data for training, the more reliable $A N N$ results. Having this in mind, one neuron in the hidden layer yielded acceptable results according to both the accuracy of the fit (minimum value of the objective function) and the predictive power of the neural network [4].

Tables 3-8 show the predicted/calculated solubility values using the ANN algorithm developed in this work along with the absolute deviations. As can be seen in Tables $3-5$, the results obtained using the ANN algorithm for methane solubility in pure water being in equilibrium with gas hydrates show less than $9 \%$ absolute deviation and the average absolute deviation among all the experimental and predicted data is $3.4 \%$. The maximum $A D$ and the $A A D$ between the experimental data and predicted data using the ANN algorithm for ethane solubility in pure water being in equilibrium with gas hydrates are about $31 \%$ and $22 \%$, respectively, as mentioned in Tables 6 and 7. The deviations are attributed to experimental data $[11,16]$, which are not temperature dependent and cannot be considered reliable. Because of unreliability of the experimental data $[11,16]$ for the ethane + water system, the pseudo-experimental data generated from the thermodynamic model were used for training the $A N N$ algorithm. Table 8 shows that using the $A N N$, the maximum $A D$ between the experimental and predicted data for propane solubility in pure water being in equilibrium with gas hydrates is below $5 \%$ and the $A D D$ equals to $1.6 \%$ [4].

Using the ANN algorithm, the solubility of $i$-butane (the heaviest pure hydrocarbon hydrate former) in pure water being in equilibrium with gas hydrates, for which there is no experimental data in the literature, was predicted. These data along with the predictions of the ANN algorithm for methane, ethane, and propane are shown in Figure 2. 
TABLE 10: Experimental [7] and predicted solubility of $\mathrm{CO}_{2}$ in water at equilibrium with gas hydrates (liquid water-hydrate equilibrium) $[3]$.

\begin{tabular}{|c|c|c|c|c|}
\hline$T / \mathrm{K}$ & $P / \mathrm{MPa}$ & $\begin{array}{c}\text { Experimental } \mathrm{CO}_{2} \\
\text { solubility [7]/mole } \\
\text { fraction }\end{array}$ & $\begin{array}{c}\text { Predicted } \mathrm{CO}_{2} \text { solubility } \\
\text { using thermodynamic } \\
\text { model/mole fraction }\end{array}$ & $A D \%$ \\
\hline 280.32 & 4.99 & 0.0256 & 0.0243 & 5.1 \\
\hline 280.59 & 6.08 & 0.0270 & 0.0249 & 7.8 \\
\hline 280.72 & 6.08 & 0.0268 & 0.0252 & 6.0 \\
\hline 280.74 & 6.08 & 0.0268 & 0.0252 & 6.0 \\
\hline 279.98 & 6.09 & 0.0262 & 0.0236 & 9.9 \\
\hline 278.71 & 6.10 & 0.0221 & 0.0211 & 4.5 \\
\hline 278.99 & 6.10 & 0.0231 & 0.0216 & 6.5 \\
\hline 279.01 & 6.10 & 0.0236 & 0.0217 & 8.1 \\
\hline 279.12 & 6.10 & 0.0232 & 0.0219 & 5.6 \\
\hline 279.32 & 6.10 & 0.0242 & 0.0223 & 7.9 \\
\hline 279.45 & 6.10 & 0.0239 & 0.0225 & 5.9 \\
\hline 279.49 & 6.10 & 0.0235 & 0.0226 & 3.8 \\
\hline 279.58 & 6.10 & 0.0249 & 0.0228 & 8.4 \\
\hline 279.94 & 6.10 & 0.0260 & 0.0235 & 9.6 \\
\hline 280.43 & 6.10 & 0.0262 & 0.0245 & 6.5 \\
\hline 280.98 & 6.10 & 0.0269 & 0.0258 & 4.1 \\
\hline 280.26 & 8.16 & 0.0268 & 0.0242 & 9.7 \\
\hline 280.34 & 10.04 & 0.0263 & 0.0244 & 7.2 \\
\hline 278.37 & 10.35 & 0.0227 & 0.0205 & 9.7 \\
\hline 278.39 & 10.35 & 0.0224 & 0.0205 & 8.5 \\
\hline 278.39 & 10.37 & 0.0223 & 0.0205 & 8.1 \\
\hline 279.18 & 10.40 & 0.0226 & 0.0220 & 2.7 \\
\hline 278.65 & 10.41 & 0.0235 & 0.0210 & 10.6 \\
\hline 279.41 & 10.43 & 0.0248 & 0.0224 & 9.7 \\
\hline 279.13 & 10.44 & 0.0241 & 0.0219 & 9.1 \\
\hline 279.60 & 10.44 & 0.0250 & 0.0227 & 9.2 \\
\hline 280.30 & 10.44 & 0.0258 & 0.0243 & 5.8 \\
\hline 280.30 & 10.44 & 0.0257 & 0.0243 & 5.4 \\
\hline 280.40 & 10.44 & 0.0260 & 0.0245 & 5.8 \\
\hline 280.00 & 10.45 & 0.0256 & 0.0236 & 7.8 \\
\hline 277.84 & 10.47 & 0.0201 & 0.0196 & 2.5 \\
\hline 280.34 & 14.20 & 0.0260 & 0.0244 & 6.2 \\
\hline
\end{tabular}

As can be observed, the ANN predicts the true behavior of solubilities of pure hydrocarbons hydrate formers in pure water being in equilibrium with gas hydrates (the solubility decreases by increasing the carbon number of pure hydrocarbon hydrate former and increases by increasing the temperature), demonstrating the capability of the ANN algorithm for modeling the $L_{W}-H$ equilibrium of water + hydrocarbon systems [4].

Finally, it should be mentioned that the $A D$ s obtained using the thermodynamic model are generally higher than the $A D$ s obtained using the ANN algorithm. This was expected, as none of the parameters of this thermodynamic model were adjusted [4].

\section{Conclusions}

We made a review on the recently developed tools by these authors for predicting the liquid water-hydrate equilibrium of the water-hydrocarbon systems. A thermodynamic model based on equality of fugacity concept was introduced for estimating the pure hydrocarbon hydrate former solubility in pure water being in equilibrium with gas hydrates. The model employed the solid solution theory of van der Waals-Platteeuw [20] for calculating the fugacity of water in the hydrate phase while Henry's law approach and the activity coefficient method were used to calculate the pure hydrocarbon hydrate former fugacity and water 
TABle 11: Number of neurons, hidden layers, parameters, data and type of activation function used in the ANN algorithm [4]. (Number of hidden layers $=1$, number of parameters $=5$, number of data used for training (and testing) $=44$, type of activation function: linear, input neurons: temperature and carbon number of single hydrocarbon hydrate former representing the type of hydrocarbon, output neuron: logarithm of solubility of single hydrocarbon hydrate former being in equilibrium with gas hydrates.)

\begin{tabular}{lc}
\hline Layer & Number of neurons \\
\hline 1 & 2 \\
2 & 1 \\
3 & 1 \\
\hline
\end{tabular}

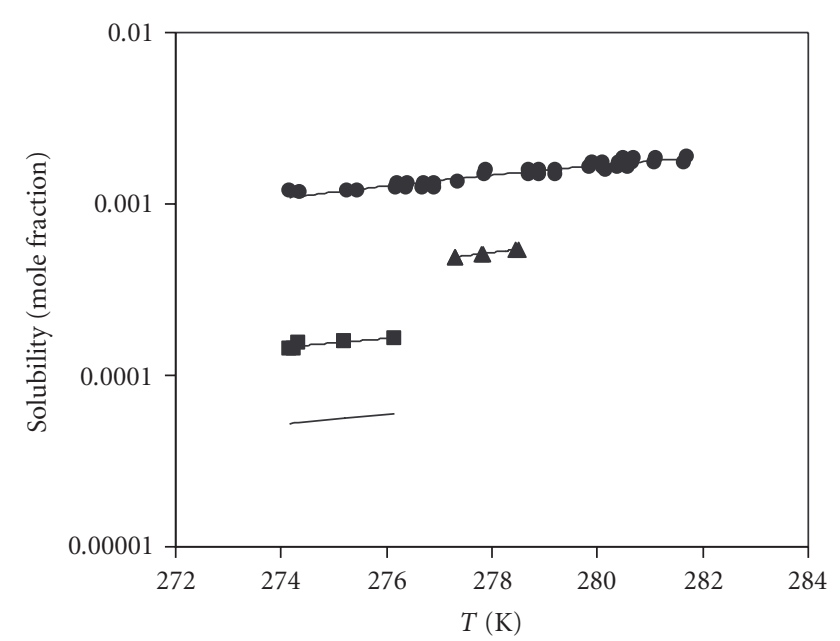

FIGURE 2: Estimated solubility of single hydrocarbon hydrate former in pure water being in equilibrium with gas hydrates. Symbols: experimental data reported in Tables 3-8. Lines: estimated values using $A N N$ algorithm (from top to bottom: methane, ethane, propane, and $i$-butane (the heaviest simple hydrocarbon hydrate former)) [4].

fugacity, respectively, in the liquid water phase. The main advantages of this model are the availability of input data and the simplicity of the calculations by ignoring the effect of pressure on the liquid water-hydrate equilibrium. The reliability of model was tested for three hydrocarbon hydrate formers: methane, ethane, and propane. Acceptable agreements were achieved between the results of this model and some selected experimental data from the literature. The study showed a need for generating reliable experimental data for the liquid water-hydrate equilibrium, especially for the systems containing heavy hydrocarbon hydrate former. The deviations of the model predictions were attributed to different factors, especially the quality of the experimental data, correlations employed for the Langmuir constants and the vapor pressures of the empty hydrate lattice, and finally expressions for the components fugacities.

Furthermore, it was shown that the model can be extended to the $\mathrm{CO}_{2}+$ water system by using an average value equal to 1.2 for the activity coefficient of water in the $\mathrm{CO}_{2}+$ water system, which eliminates any need to use a model for the activity coefficient of water. This value was already assumed equal to unity for the single hydrocarbon hydrate former + water system.

A feed-forward artificial neural network algorithm with one hidden layer, which uses a modified LevenbergMarquardt optimization algorithm [38, 39], was developed for estimating the solubility of single hydrocarbon hydrate former in pure water being in equilibrium with gas hydrates. This algorithm has one output neuron (logarithm of solubility of single hydrocarbon hydrate former in pure water being in equilibrium with gas hydrates), two input neurons (temperature and carbon number of hydrocarbon hydrate former, which represents the type of hydrocarbon) and one neuron in the hidden layer taking advantage of a linear activation function. The model was trained and developed using more recent and reliable data reported in the literature and its predictions were successfully compared with some independent experimental data (not used in developing the artificial neural network algorithm) for three hydrate formers: methane, ethane, and propane.

\section{Nomenclature}

$A A D$ : Average absolute deviation $\left(A A D=(1 / M) \sum_{i}^{M} \mid(\right.$ experimental value predicted/calculated value)/ experimental value $\mid$ )

$A D$ : Absolute deviation $(A D=\mid$ (experimental value predicted/calculated value)/ experimental value|)

ANN: Artificial neural network

CNG: Compressed natural gas

FNN: Feed-forward (back propagation) neural network

$L N G$ : Liquefied natural gas

A: $\quad$ Parameter of Henry's constant correlation

B: Parameter of Henry's constant correlation

C: $\quad$ Langmuir constant

$\bar{C}: \quad$ Parameter of Henry's constant correlation

D: Parameter of Henry's constant correlation

$H$ : Hydrate

$\bar{H}$ : $\quad$ Henry's constant

I: $\quad$ Input vector

L: $\quad$ Liquid

$M: \quad$ Number of experimental data

$N$ : Number of feed inputs

O: Output

$P$ : $\quad$ Pressure

$R: \quad$ Universal gas constant

$S: \quad$ Weighted sum

T: $\quad$ Temperature

$V: \quad$ Vapor

a: Parameter of Langmuir constant correlation

$b$ : Parameter of Langmuir constant correlation

$\bar{b}: \quad$ Bias 
c: Parameter of Langmuir constant correlation

$d$ : Parameter of Langmuir constant correlation

$f$ : Fugacity

$\bar{f}$ : Activation function

$k$ : Layer

$v$ : Molar volume

$v_{i}^{\prime}$ : Number of cavities of type $i$ per water molecule in a unit hydrate cell

$w$ : Weight parameter between each neuron-neuron interconnection

$x$ : Mole fraction in the liquid phase.

$\bar{x}$ : Parameter of activation function

\section{Greek Letters}

$\mu$ : Chemical potential

$\gamma$ : Activity coefficient

$\varphi$ : Correction parameter

\section{Superscripts}

$M T$ : Hypothetical empty hydrate

$H$ : Hydrate

L: $\quad$ Liquid state

Sat: Saturation condition

\section{Subscripts}

HC: Hydrocarbon hydrate former

exp: Experimental data

max: Maximum value

min: Minimum value

g: $\quad$ Gas

$w, W$ : Water

\section{References}

[1] E. D. Sloan, Clathrate Hydrates of Natural Gases, Marcel Dekker, New York, NY, USA, 2nd edition, 1998.

[2] A. H. Mohammadi and D. Richon, "Thermodynamic model for predicting liquid water-hydrate equilibrium of the waterhydrocarbon system," Industrial \& Engineering Chemistry Research, vol. 47, no. 4, pp. 1346-1350, 2008.

[3] A. H. Mohammadi, Personal communication 2008.

[4] A. H. Mohammadi and D. Richon, "A mathematical model based on artificial neural network technique for estimating liquid water-hydrate equilibrium of water-hydrocarbon system," Industrial \& Engineering Chemistry Research, vol. 47, no. 14, pp. 4966-4970, 2008.

[5] P. Jadhawar, A. H. Mohammadi, J. Yang, and B. Tohidi, "Subsurface $\mathrm{CO}_{2}$ storage through hydrate formation," in Proceeding of the Advanced Research Workshop (ARW'04), Tomsk, Russia, November 2004.

[6] S. Hashemi, A. Macchi, S. Bergeron, and Ph. Servio, "Prediction of methane and carbon dioxide solubility in water in the presence of hydrate," Fluid Phase Equilibria, vol. 246, no. 1-2, pp. 131-136, 2006.

[7] S. O. Yang, I. M. Yang, Y. S. Kim, and C. S. Lee, "Measurement and prediction of phase equilibria for water $+\mathrm{CO}_{2}$ in hydrate forming conditions," Fluid Phase Equilibria, vol. 175, no. 1-2, pp. 75-89, 2000.

[8] S. O. Yang, S. H. Cho, H. Lee, and C. S. Lee, "Measurement and prediction of phase equilibria for water + methane in hydrate forming conditions," Fluid Phase Equilibria, vol. 185, no. 1-2, pp. 53-63, 2001.

[9] Ph. Servio and P. Englezos, "Effect of temperature and pressure on the solubility of carbon dioxide in water in the presence of gas hydrate," Fluid Phase Equilibria, vol. 190, no. 1-2, pp. 127-134, 2001.

[10] Ph. Servio and P. Englezos, "Measurement of dissolved methane in water in equilibrium with its hydrate," Journal of Chemical \& Engineering Data, vol. 47, no. 1, pp. 87-90, 2002.

[11] Y. S. Kim, S. K. Ryu, S. O. Yang, and C. S. Lee, "Liquid waterhydrate equilibrium measurements and unified predictions of hydrate-containing phase equilibria for methane, ethane, propane, and their mixtures," Industrial \& Engineering Chemistry Research, vol. 42, no. 11, pp. 2409-2414, 2003.

[12] Y. P. Handa, "Effect of hydrostatic pressure and salinity on the stability of gas hydrates," The Journal of Physical Chemistry, vol. 94, no. 6, pp. 2652-2657, 1990.

[13] O. Y. Zatsepina and B. A. Buffett, "Phase equilibrium of gas hydrate: implications for the formation of hydrate in the deep sea floor," Geophysical Research Letters, vol. 24, no. 13, pp. 1567-1570, 1997.

[14] A. L. Ballard and E. D. Sloan Jr., "The next generation of hydrate prediction: I. Hydrate standard states and incorporation of spectroscopy," Fluid Phase Equilibria, vol. 194-197, pp. 371-383, 2002.

[15] A. L. Ballard, A non-ideal hydrate solid solution model for a multi-phase equilibria program, Ph.D. thesis, Colorado School of Mines, Golden, Colo, USA, 2002.

[16] S. O. Yang, Measurements and prediction of phase equilibria for water + natural gas components in hydrate-forming conditions, Ph.D. thesis, Korea University, Seoul, South Korea, December 2000.

[17] Y. Seo, H. Lee, and B.-J. Ryu, "Hydration number and twophase equilibria of $\mathrm{CH}_{4}$ hydrate in the deep ocean sediments," Geophysical Research Letters, vol. 29, no. 8, article 1244, pp. 185, 2002.

[18] I. M. Chou and R. C. Burruss, personal communication, December 2006.

[19] J. Gaudette and Ph. Servio, "Measurement of dissolved propane in water in the presence of gas hydrate," Journal of Chemical \& Engineering Data, vol. 52, no. 4, pp. 1449-1451, 2007.

[20] J. H. van der Waals and J. C. Platteeuw, "Clathrate solutions," in Advances in Chemical Physics, vol. 2, pp. 1-57, John Wiley \& Sons, New York, NY, USA, 1959.

[21] M. von Stackelberg and H. R. Müller, "Feste gashydrate II: structur und raumchemie," Zeitschrift für Elektrochemie, vol. 58, pp. 25-39, 1954.

[22] B. E. Poling, J. M. Prausnitz, and R. Reid, Properties of Gases and Liquids, McGraw-Hill, New York, NY, USA, 5th edition, 2000.

[23] J. I. Lunine and D. J. Stevenson, "Thermodynamics of clathrate hydrate at low and high pressures with application to the outer solar system," The Astrophysical Journal Supplement Series, vol. 58, no. 3, pp. 493-531, 1985.

[24] W. R. Parrish and J. M. Prausnitz, "Dissociation pressures of gas hydrates formed by gas mixtures," Industrial \& Engineering Chemistry Process Design and Development, vol. 11, no. 1, pp. 26-35, 1972. 
[25] T. Kihara, "Virial coefficients and models of molecules in gases," Reviews of Modern Physics, vol. 25, no. 4, pp. 831-843, 1953.

[26] V. McKoy and O. Sinanoğlu, "Theory of dissociation pressures of some gas hydrates," The Journal of Chemical Physics, vol. 38, no. 12, pp. 2946-2956, 1963.

[27] P. B. Dharmawardhana, W. R. Parrish, and E. D. Sloan, "Experimental thermodynamic parameters for the prediction of natural gas hydrate dissociation conditions," Industrial \& Engineering Chemistry Fundamentals, vol. 19, no. 4, pp. 410$414,1980$.

[28] A. Chapoy, A. H. Mohammadi, A. Valtz, C. Coquelet, and D. Richon, "Water and inhibitor distribution in gas production systems," GPA Research Project 987, GPA, Tulsa, Okla, USA, 2008.

[29] T. E. Daubert and R. P. Danner, DIPPR Data Compilation Tables of Properties of Pure Compounds, AIChE, New York, NY, USA, 1985.

[30] A. Normandin, B. P. A. Grandjean, and J. Thibault, "PVT data analysis using neural network models," Industrial \& Engineering Chemistry Research, vol. 32, no. 5, pp. 970-975, 1993.

[31] F. Rivollet, Etude des propriétés volumétriques (PVT) d'hydrocarbures légers (C1-C4), du dioxyde de carbone et de l'hydrogène sulfuré: mesures par densimétrie à tube vibrant et modélisation, Ph.D. thesis, School of Mines, Paris, France, December 2005.

[32] B. Wilamowski, S. Iplikci, O. Kayank, and M. O. Efe, "An algorithm for fast convergence in training neural networks," in Proceedings of the International Joint Conference on Neural Networks (IJCNN'01), pp. 1778-1782, Washington, DC, USA, July 2001.

[33] A. Chouai, S. Laugier, and D. Richon, "Modeling of thermodynamic properties using neural networks: application to refrigerants," Fluid Phase Equilibria, vol. 199, no. 1-2, pp. 5362, 2002.

[34] L. Piazza, G. Scalabrin, P. Marchi, and D. Richon, "Enhancement of the extended corresponding states techniques for thermodynamic modeling. I. Pure fluids," International Journal of Refrigeration, vol. 29, no. 7, pp. 1182-1194, 2006.

[35] G. Scalabrin, P. Marchi, L. Bettio, and D. Richon, "Enhancement of the extended corresponding states techniques for thermodynamic modeling. II. Mixtures," International Journal of Refrigeration, vol. 29, no. 7, pp. 1195-1207, 2006.

[36] J. E. Schmitz, R. J. Zemp, and M. J. Mendes, "Artificial neural networks for the solution of the phase stability problem," Fluid Phase Equilibria, vol. 245, no. 1, pp. 83-87, 2006.

[37] A. Chapoy, A. H. Mohammadi, and D. Richon, "Predicting the hydrate stability zones of natural gases using artificial neural networks," Oil \& Gas Science and Technology, vol. 62, no. 5, pp. 701-706, 2007.

[38] D. Marquardt, "An algorithm for least-squares estimation of nonlinear parameters," SIAM Journal on Applied Mathematics, vol. 11, no. 2, pp. 431-441, 1963.

[39] K. Levenberg, "A method for the solution of certain problems in least squares," Quarterly of Applied Mathematics, vol. 2, pp. 164-168, 1944. 

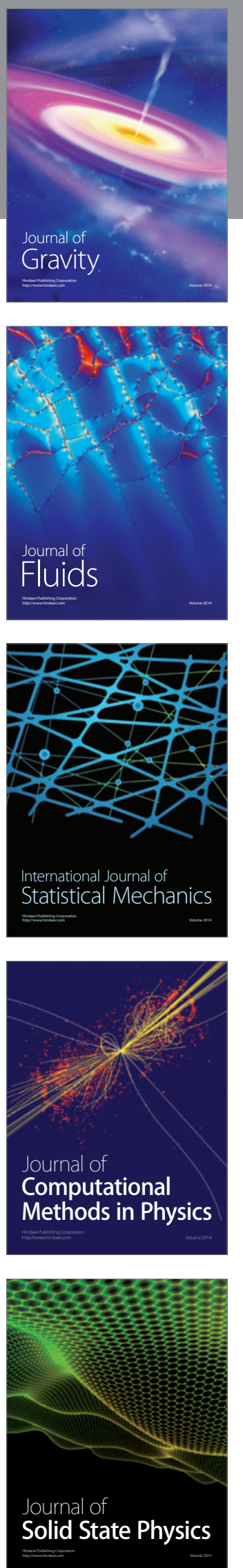

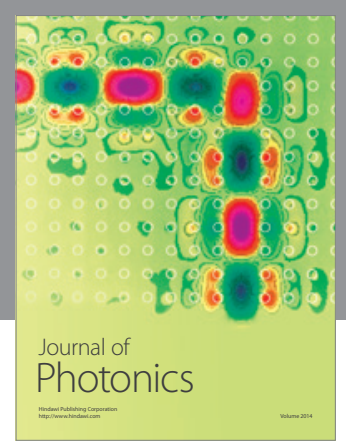

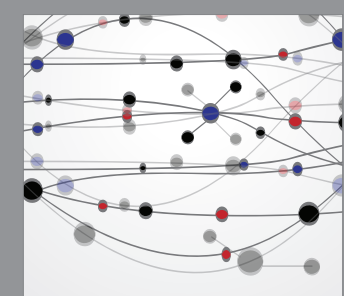

The Scientific World Journal
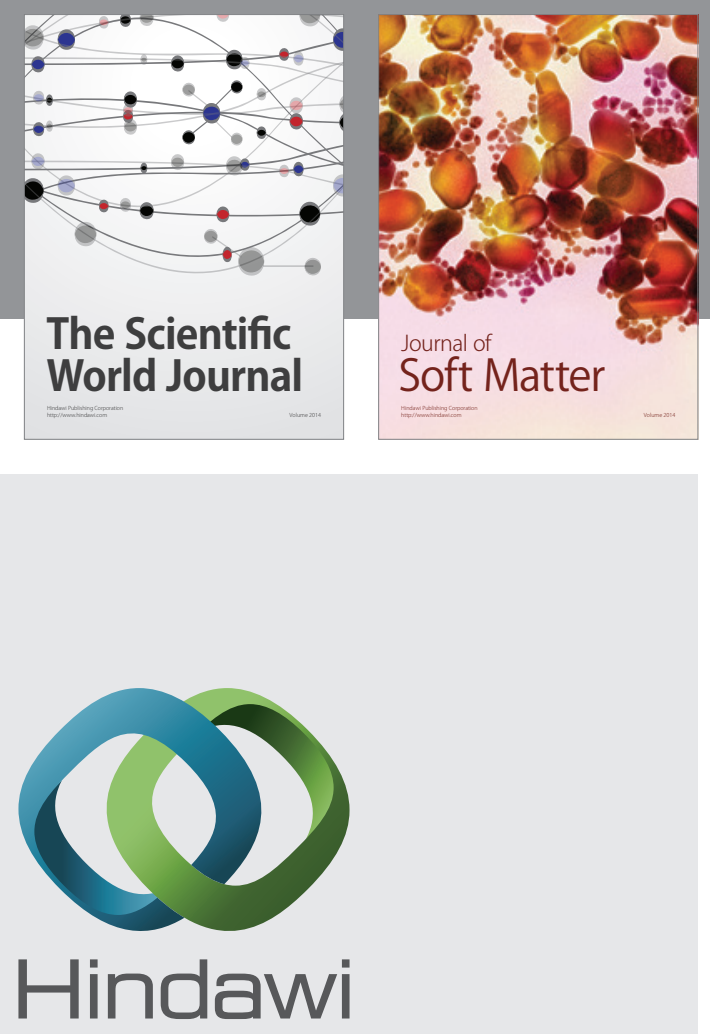

Submit your manuscripts at

http://www.hindawi.com
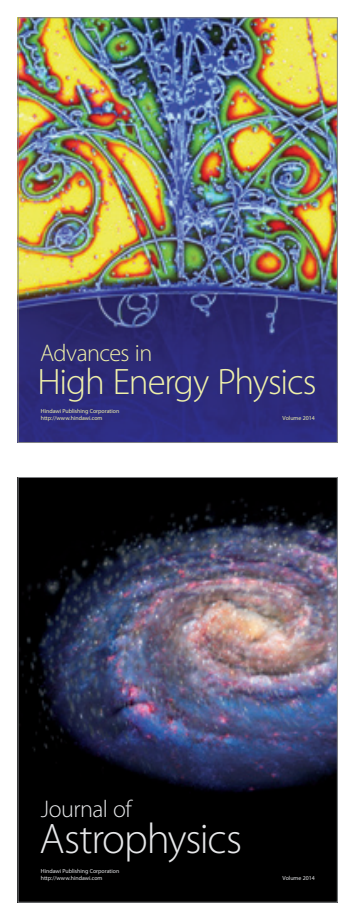
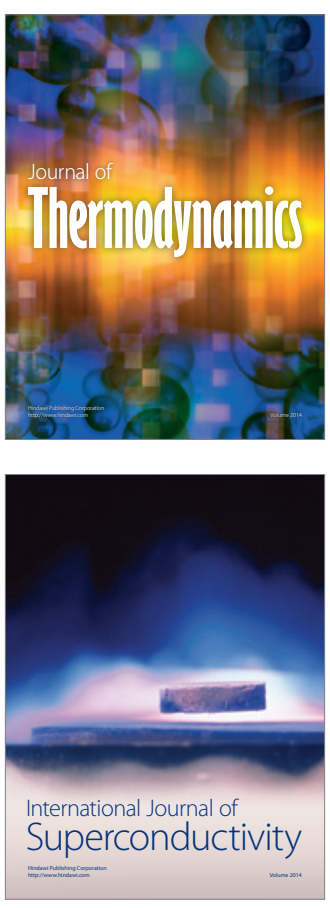
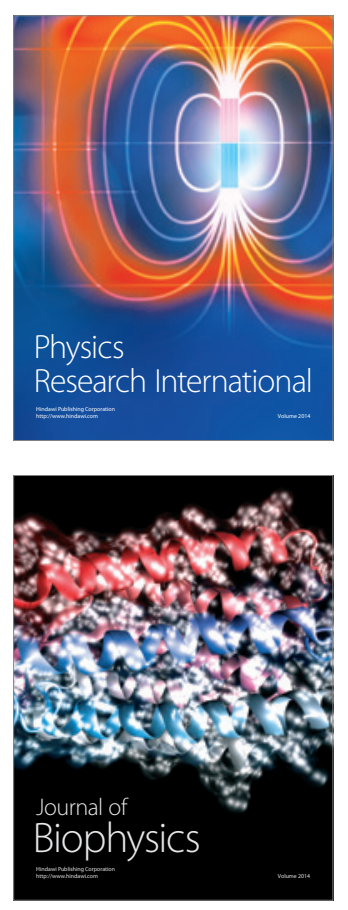
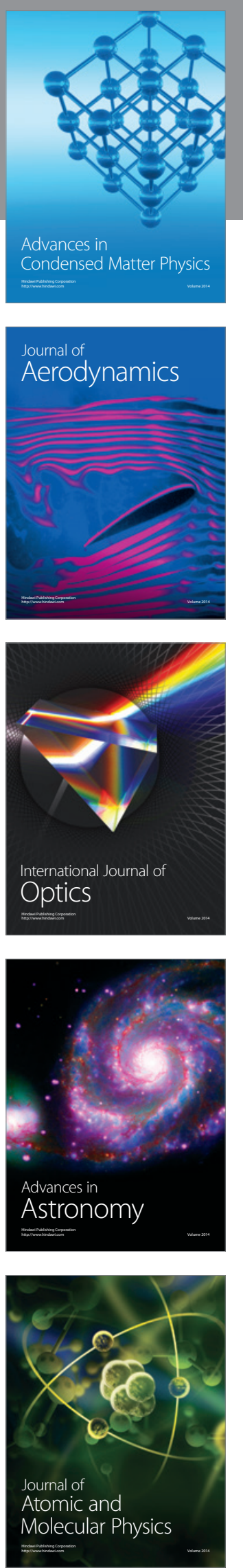